\title{
MANAJEMEN PENGELOLAAN MASJID DAN PEMBERDAYAAN \\ REMAJA MASJID DARUL ARQOM - KH. AHMAD DAHLAN \\ SIDOMULYO-MAKAMHAJI-KARTASURA \\ KABUPATEN SUHOHARJO
}

\section{Djoko Kristianto dan Riska Fii Ahsani}

\begin{abstract}
Abstraksi
Permasalahan yang sering muncul adalah masih belum bagusnya dalam pengelolaan masjid, program kerja yag belum dibuat dengan sebaik mungkin, pengkaderan generasi muda yang stagnan, sehingga dapat menyebabkan belum tersentuhnya permasalaham jamaah masjid. Selain hal tersebut di atas pembinaan remaja masjid dan pengelolaan masjid belum menggunakan manajeman yang baik. Tujuan dalam pengabdian adalah (1) Bagaimana mengelola masjid dengan manajemen modern dan mencontoh fungsi masjid pada zaman Rasulullah SAW (2) Pembinaan remaja masjid. Luaran yang dihasilkan adalah (1) publikasi jurnal ilmiah (2) peningkatan kemampuan dalam mengelola atau memanaj masjid (3) penyusunan program kerja masjid (4) peningkatan ketrampilan remaja masjid dalam berorganisasi terutama untuk memakmurkan masjid.

Kata kunci : Manajemen penelolaan masjid, program kerja masjid, pemberdayaan
\end{abstract}

\section{A. Pendahuluan}

Salah satu orang yang akan mendapatkan naungan pertolongan dari Alloh SWT di hari kiamat adalah pemuda yang hatinya tertambat pada masjid dan memakmurkannya. Tetapi dengan adanya kemajuan zaman dengan segala macam permasalahannya ternyata berimbas pula pada kondisi masjid pada zaman sekarang. Dahulu akan sangat mudah mendapatkan anak-anak remaja yang menjadikan masjid sebagai tempat untuk beribadah, berkumpul dan ber-interkasi dengan teman-temannya. Dengan seringnya berinteraksi biasanya akan muncul berbagai macam ide untuk melakukan kegiatan-kegiatan yang bertujuan untuk memakmurkan masjid, misalnya mengadakan kajian sore dari maghrib sampai dengan waktu isya, mengadakan lomba baca quran, lomba adzan, praktik sholat dan wudhu, bahkan yang berhubungan dengan fisik seperti lomna mencari jejak, 
dan lain sebagainya. Tetapi dengan berjalannya waktu kehidupanpun mulai perlahan telah mengalami perubahan. Anak-anak dan remaja mulai meninggalkan masjid dan beralih berinteraksi di mall, warnet, game on line dan hand pone. Akibatnya masjid zaman sekarang lebih banyak di fungsikan sebagai tempat untuk ibadah sholat saja. Oleh sebab itu dengan perkembangan zaman yang begitu pesat dan semakin kerasnya kehidupan, seharusnya segera di antisipasi sesegara mungkin. Dengan semakian majunya ilmu pengetahuan, perlu kiranya juga memberdayakan remaja dan dilibatkan dalam pengelolaan masjid dengan sebaikbaiknya. Karena hal tersebut sangat penting bagi keberlangsungan kemaslakatan ummat. Kerasnya gelombang budaya asing yang bersifat destruktif mendorong para pengelola masjid untuk mempersiapkan Manajemen yang baik dan berkualitas.

Manajemen masjid yang kita siapkan, tidak lepas dari tuntunan al-Qur'an dan al-Sunnah, dari kedua sumber ajaran Islam itulah kita mengembangkan suatu manajemen pengelolaan masjid yang sesuai dengan bimbingan Rasulullah saw. Sebagai suatu aktivitas yang sangat terpuji, pengelolaan masjid harus dilaksanakan secara profesional dan menuju pada sistem manajemen modern, sehingga dapat mengantisipasi perkembangan yang terus berubah dalam kehidupan masyarakat yang maju dan berkualitas. Masjid merupakan suatu organisasi yang menjadi pusat ibadah, da'wah dan peradaban Islam, untuk pengelolaannya agar lebih efisien dan efektif perlu menggunakan ilmu Manajemen. Ilmu manajemen pada awalnya tumbuh dan berkembang dikalangan dunia bisnis, industri dan militer, akan tetapi dalam perkembangan selanjutnya ternyata sangat bermanfaat dan amat dibutuhkan dalam berbagai usaha dan kegiatan, termasuk didalamnya organisasi pengelolaan masjid. Begitu juga pada masjid Darul Arqom dan KH. Ahmad Dahlan, di Desa Sidomulyo Makamhaji Kartasura Kabupaten Sukoharjo, remaja sebagai calon penerus harapan agama memeliki potensi untuk mengembangkan masjid agar di masa sekarang dan masa yang akan datang lebih berdaya guna demi kemakmuran dan kejayaan umat Islam.

Didalam pengabdian pada masyasrakat ini yang dituju adalah pengurus masjid dan remaja masjid. Dilihat dari kondisi fisik bangunan sungguh sangat megah dan remaja masjid, cukup potensial untuk di kembangkan . Oleh karena 
itu dalam program pengabdian kepada masyarakat perlu diberikan penyuluhan kepada remaja masjid agar dapat memberdayakan kapasistas yang dimilikinya dengan baik dan memiliki kemampuan untuk mengelola masjid dengan baik, sehingga diharapkan dapat menjadi generasi penerus sehingga dapat meningkatkan pemahaman dalam mengelola sehingga masjid dapat dijadikan pusat kegiatan masyarakat yang selalu hatinya terikat untuk memakmurkan masjid. Permasalahan mitra adalah masih belum bagusnya dalam manajemen pengelolaan masjid, program kerja yag belum dibuat dengan baik, pengkaderan generasi muda yang stagnan.

\section{B. Solusi Mitra Masjid Darul Arqom dan Masjid KH. Ahmad Dahlan}

\begin{tabular}{|c|lr|lr|}
\hline No & \multicolumn{1}{|c|}{ Permasalahan } & \multicolumn{2}{|c|}{ Solusi Program } \\
\hline 1 & $\begin{array}{l}\text { Manajemen Pengeloloaan } \\
\text { Masjid }\end{array}$ & $\begin{array}{l}\text { Penyuluhan Pengelolaan Manajemen } \\
\text { Masjid }\end{array}$ \\
\hline 2 & $\begin{array}{l}\text { Program kerja yang belum } \\
\text { baik }\end{array}$ & $\begin{array}{l}\text { Penyuluhan pembuatan program } \\
\text { kerja masjid }\end{array}$ \\
\hline 3 & Pemberdayaan remaja masjid & $\begin{array}{l}\text { Penyuluhan Pemberdayaan remaja } \\
\text { masjid }\end{array}$ \\
\hline
\end{tabular}

\section{Target dan Luaran}

Target atau Sasaran yang dilibatkan dalam penyuluhan ini adalah pengurus dan remaja masjid yang ikut sebagai pengelola masjid Darul Arqom dan Masjid KH. Ahmad Dahlan. Luaran yang dihasilkan adalah (1) publikasi jurnal ilmiah (2) peningkatan kemampuan dalam mengelola atau memanaj masjid (3) penyusunan program kerja masjid (4) peningkatan ketrampilan remaja masjid dalam berorganisasi terutama untuk memakmurkan masjid.

\section{METODE PELAKSANAAN}

\section{A. Sasaran}

Sasaran yang dilibatkan dalam penyuluhan ini adalah pengurus dan remaja masjid yang ikut sebagai pengelola masjid Darul Arqom dan Masjid KH. Ahmad Dahlan. 


\section{B. Metode Kegiatan}

Pengabdian masyarakat kepada pengurus dan remaja masjid darul Arqom dan KH Ahmad Dahlan adalah upaya untuk memberikan penyuluhan bagaimana mengelola masjid, menyusun prrogram kerja masjid dan pemberdayaan remaja masjid. Permasalahan yang muncul adalah masih belum bagusnya dalam pengelolaan masjid, program kerja yag belum dibuat dengan sebaik mungkin, pengkaderan generasi muda yang stagnan, sehingga dapat menyebabkan belum tersentuhnya permasalaham jamaah masjid. Untuk memudahkan pemahaman metode kegiatan, maka dapat di terangkan dengan gambar sebagai berikut :

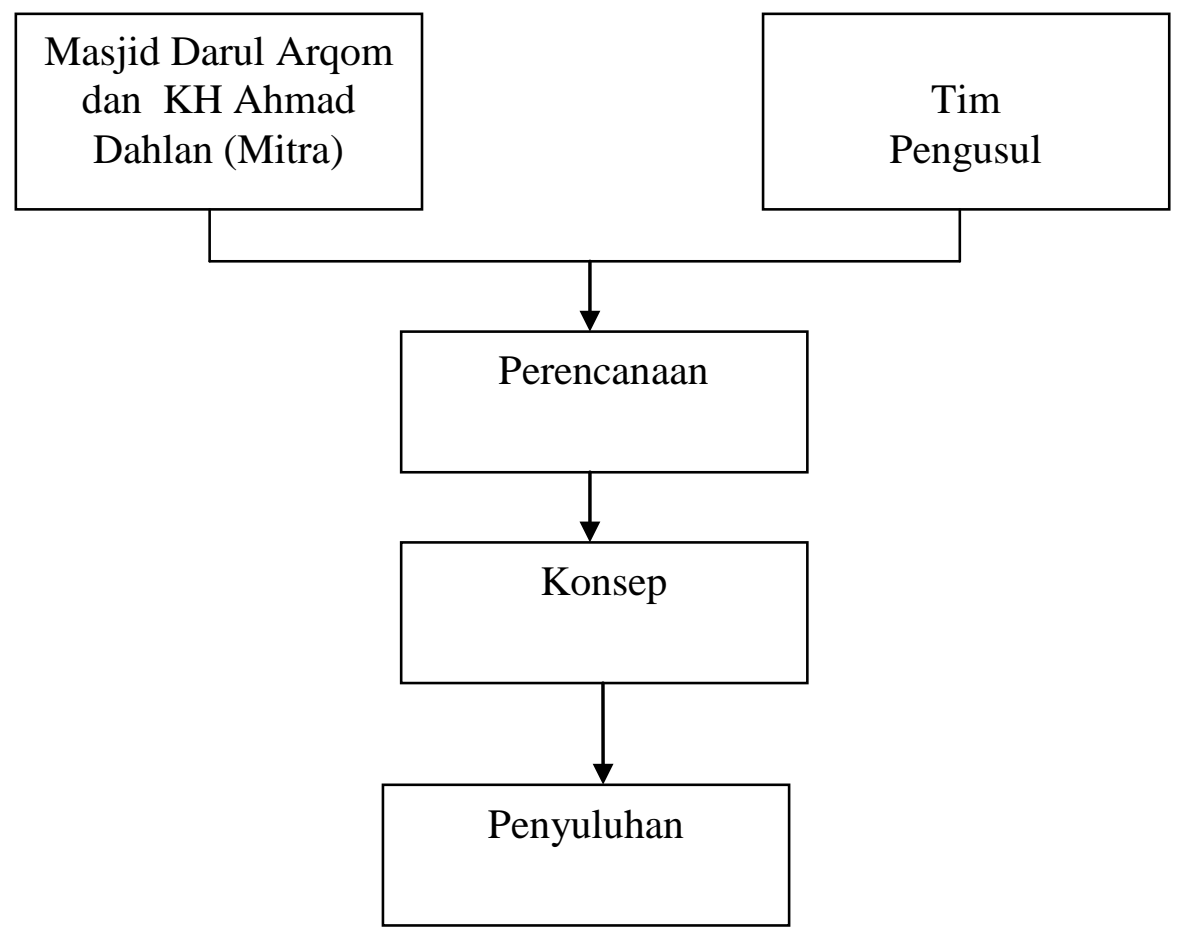

Selain hal tersebut di atas pembinaan remaja masjid dan pengelolaan masjid belum menggunakan manajeman yang baik.

\section{Evaluasi}

Berdasarkan hal tersebut di atas maka dapat di evaluasi sebagai berikut : :

1. Bagaimana seharusnya mengelola masjid

2. Bagaimana penyusunan program kerja masjid

3. Bagaimana Pemberdayaan remaja masjid

4. Bagaimana kegiatan mitra 
5. Keberlanjutan dari program pengabdian pada masyarakat

Lembaga penelitian dan pengabdian masyrakat Universitas Slamet Riyadi Surakarta di dalam penyuluhan ini telah banyak melakukan kegiatan khusunya pengabdian kepada masyarakat, seperti kerjasama dengan masyarakat di sekitar UNISRI. Terdapat tiga materi utama yang akan disampaikan yaitu : (1) Bagaimana mengelola masjid dengan manajemen modern dan mencontoh fungsi masjid pada zaman Rasulullah SAW (2) Menyusun program kerja masjid dan (3) Pemberdayaan remaja masjid. Sedangkan peserta adalah pengurus dan remaja masjid Darul Arqom dan KH Ahmad Dahlan dengan jumlah pesrta sekitar 20 orang. Metode kegiatan adalah penyuluhan tentang bagaimana mengelola masjid, menyusun program kerja dan pemberdayaan remaja masjid. Penyuluhan yang dilakukan menuntut pengalaman yang cukup luas dari para motivator, kalau hanya teori saja tentu kurang memadai, tetapi karena motivator memiliki pengalaman yang cukup memadai dan juga sebagai organisatoris, jamaah masjid, tentu masalah tersebut bukanlah masalah yang cukup berat. Pengalaman selama hidup ditengah masyarakat sangat membantu pelatihan tersebut, sehingga setelah pelatihan, ilmu yang didapatkan langsung bisa diterapkan oleh para peserta. Didalam melaksanakan kegiatan penyuluhan ini tim pelaksanaan berusaha melakukan kegiatan sesuai dengan dan jadwal yang telah direncanakan. Meskipun begitu dalam praktinya terdapat kendala, yaitu kedatangan perserta yang tidak semua tepat waktu, sehingga acaranya pun selesai tidak dapat sesuai dengan waktu yang disepakati, tetapi secara umum pelaksanaan penyuluhan tersebut berjalan dengan baik dan tidak ada kendala yang begitu berat semua dapat berjalan dengan baik.

\section{HASIL YANG DICAPAI}

Hasil yang dicapai selama pelaksanaan tersebut adalah tiap peserta penyuluhan memahami, bagaimana mengelola masjid, menyusun program kerja masjid dan pemberdayaan remaja masjid. Sedangkan peserta adalah pengurus dan remaja masjid Darul Arqom dan KH Ahmad Dahlan dengan jumlah peserta sekitar 20 orang. Metode kegiatan adalah penyuluhan tentang bagaimana mengelola masjid, menyusun program kerja dan pemberdayaan remaja masjid. 
Maka nanti akan kelihatan bagaimana seharusnya mengelola masjid, penyusunan program kerja masjid, pemberdayaan remaja masjid, serta bagaimana keberlanjutan dari program pengabdian pada masyarakat.

Pelaksanaan evaluasi akan dilaksanakan pada akhir kegiatan dan indikator yang digunakan untuk melihat berhasil tidaknya pelaksanaan yaitu dengan melihat respon serta aktivitas peserta untuk menambah tingkat pemahaman bagaimana pengelolaan masjid, program kerja yag belum dibuat dengan sebaik mungkin, pengkaderan generasi muda yang stagnan, sehingga dapat menyebabkan belum tersentuhnya permasalaham jamaah masjid. Selain hal tersebut di atas pembinaan remaja masjid dan pengelolaan masjid belum menggunakan manajeman yang baik. Setelah kegiatan penyuluhan selesai, direncanakan aka ada kegiatan penyuluhan lanjutan, tentang bagaimana membuat program kerja untuk memakmurkan masjid. Sedangkan peserta adalah pengurus dan remaja masjid Darul Arqom dan KH Ahmad Dahlan. Disamping itu akan diadakan evaluasi terhadap metode dan hasil penyuluhan, diharapkan dengan adanya evaluasi akan dapat di ketahuai keefektifan kegiatan pelaksanaan tersebut, selanjutnya akan ditindak lanjuti untuk diadakan perbaikan. Bagaimanpun masjid merupakan suatu organisasi yang menjadi pusat ibadah, da'wah dan peradaban Islam, maka di dalam pengelolaannya masjid harus dikelola secara professional, dan perlu menggunakan ilmu Manajemen.

Ilmu manajemen pada awalnya tumbuh dan berkembang dikalangan dunia bisnis, industri dan militer, akan tetapi dalam perkembangan selanjutnya ternyata sangat bermanfaat dan amat dibutuhkan dalam berbagai usaha dan kegiatan, termasuk didalamnya organisasi pengelolaan masjid. Begitu juga pada masjid Darul Arqom dan KH. Ahmad Dahlan, di Desa Sidomulyo Makamhaji Kartasura Kabupaten Sukoharjo, dengan harapan agar pengurus dan remaja masjid memeliki potensi untuk mengembangkan masjid agar di masa sekarang dan masa yang akan datang lebih berdaya guna demi kemakmuran dan kejayaan umat Islam. 


\section{KESIMPULAN DAN SARAN}

\section{Kesimpulan}

Kesimpulan hasil yang dicapai selama pelaksanaan tersebut adalah tiap peserta penyuluhan di arahkan untuk realitis, praktis dalam mengelola masjid dengan manajemen yang baik dan pengelolaan yang baik. Selanjutnya dipusatkan bekal apa yang harus disiapkan oleh pengurus dan remaja masjid Darul Arqom dan $\mathrm{KH}$ Ahmad Dahlan, bagaimana seharusnya mengelola masjid, penyusunan program kerja masjid, pemberdayaan remaja masjid, serta bagaimana keberlanjutan dari program pengabdian pada masyarakat. Peserta sangat antusias mengikuti acara penyuluhan manajemen masjid dan pengelolaan masjid bagi pengurus dan remaja masjid Darul Arqom dan KH Ahmad Dahlan. Terdapat beberapa kendala diantaranya memahami pentingnya pengelolaan manajemen dan pengelolaan masjid bagi pengurus dan remaja masjid Darul Arqom dan KH Ahmad Dahlan.

\section{Saran}

Ada beberapa saran yang dapat kami simpulkan dalam kegitan pelatihan tersebut di anatranya adalah, hendaknya terdapat pertemuan rutin pengurus dan remaja masjid Darul Arqom dan KH Ahmad Dahlan dalam pengelolaan masjidnya,perlu dilakukan monitoring dan evaluasi bagimana strategi yang harus disiapkan oleh pengurus dan remaja masjid Darul Arqom dan KH Ahmad Dahlan, bagaimana seharusnya mengelola masjid, penyusunan program kerja masjid, pemberdayaan remaja masjid, serta bagaimana keberlanjutan agar masjid nanti tetap makmur.

\section{Daftar Pustaka}

Asfari, Memakmurkan masjid di Kecamatan Wuryantoro

Bachrun Rifa'I dan Moch. Fakhruroji, 2005, Manajemen Masjid Mengoptimalkan Fungsi Sosial Ekonomi Masjid. Bandung : Benang Merah Press. Hlm. 51 Hlm. 44.

Ahmad Yani, 2009, Panduan Memakmurkan Masjid, Jakarta : Al qalam. Hlm. 19.

Budiman Mustofa, 2008, Manajemen Masjid, Surakarta : Ziyad Books.

Supriyanto Abdullah, 1997, Peran dan Fungsi Masjid, Yogyakarta : Cahaya Hikmah. Hlm. 10.

Moh. E. Ayub, Muhsin dan Ramlan Mardjoned, 1996, Manajemen Masjid, Jakarta : Gema Insani Press. Hlm. 8. 
Asep Usman Ismail dan Cecep Castrawijaya, 2010, Manajemen Masjid, Bandung : Angkasa Bandung. Hlm. 4.

Nur Wahid, Manajemen Masjid SEKOLAH TINGGI AGAMA ISLAM NEGERI (STAIN) PURWOKERTO

DR. KH. Zakky Mubarrak, MA.Manajemen Pengelolaan Masjid 